\title{
Routine and reflexivity: Simonian cognitivism vs practice approach
}

\section{Rouslan Koumakhov $^{1, *}$ and Adel Daoud ${ }^{2}$}

${ }^{1}$ NEOMA Business School, Campus Reims, 59 rue Pierre Taittinger, 51100 Reims, France. e-mail: rouslan.koumakhov@neoma-bs.fr and ${ }^{2}$ Cambridge Judge Business School, University of Cambridge, Trumpington Street, Cambridge CB2 1AG, UK. e-mail: ad836@cam.ac.uk

*Main author for correspondence.

\begin{abstract}
The proponents of practice approaches to organizational routines claim that Herbert Simon's conceptualization of routines overlooks issues of mindfulness, agency, and interpretation. We show that this criticism of Simon's account of rule-based behavior in organizations is unsound. More importantly, Simon's account overcomes some serious limitations of practice approaches with regard to understanding reflexivity, subjectivity, and improvisation. We reconstruct Simon's view of organizational rules and cognition as part of his decision-making theory. In this view, rules are not rigid repetitive patterns of action, but mental structures allowing for various degrees of subjective interpretation, behavioral flexibility, and strategic action. We emphasize the central place that Simon assigns to the concept of a shared cognitive model governing representations of reality, and the importance of this concept in understanding the issue of rule-based behavior. Simon's analysis is contemporary and powerful, insofar as it offers a valuable and comprehensive alternative to current understandings of routine and cognition in organizations.
\end{abstract}

JEL classification: B4, D23, D7, M10

"A body of theory for procedural rationality is consistent with a world in which human beings continue to think and continue to invent."

MPIfG Journal Article

Rouslan Koumakhov, Adel Daoud: Routine and Reflexivity: Simonian Cognitivism vs Practice Approach. In: Industrial and Corporate

Change 26(4), 727-743 (2017). Oxford University Press

The original publication is available at the publisher's web site: http://doi.org/10.1093/icc/dtw048

\section{Introduction}

The MPIfG Journal Articles series features articles by MPIfG researchers and visiting scholars published in peer-reviewed journals. (Simon, 1976: 146)

Max Planck Institute for the Study of Societies (MPIfG) Cologne | www.mpifg.de

Herbert Simon is habitually credited with the idea that routines, viewed as recurrent behavioral patterns, play a central role in organizations. The dominant opinion appears to be that Simon's organizational routines prescribe more or less detailed actions and are applied with minimum (or with no) reflexivity. Accordingly, there is a strong dichotomy in organizational activities between (nearly) automatic application of such routines—enabling actors to economize on cognition-and cognitive activities per se, such as the elaboration of new routines. In this dominant opinion, the resulting Simonian account of organizational behavior does not strongly emphasize subjectivity, cognitive liberty, and individual interpretative abilities. Two books are usually referenced as exemplifying this conceptualization: Administrative Behavior (Simon, 1947/1997, hereafter AB) and his work with James March (March and Simon, 1958/1993). 
These ideas might suggest that Simon's work is outdated, in the face of various reconceptualizations of organizational routine with their focus on change, agency, and mindfulness (e.g., Feldman, 2000; Feldman and Pentland, 2003; Becker, 2004; Becker et al., 2005; Pentland and Feldman, 2005; Reynaud, 2005; Howard-Grenville, 2005; Levinthal and Rerup, 2006; Cohen, 2007; Gavetti et al., 2007; Greve, 2007; D’Adderio, 2008; Felin and Foss, 2011; Lazaric, 2011; Parmigiani and Howard-Grenville, 2011; Felin et al., 2012; Pentland et al., 2012; Winter, 2013; Cohen et al., 2014). Of course, not all these authors subscribe to such skepticism. However, the increasingly prevailing view is that Simon's organizational routines are "mindless repetitions" (Reynaud, 2005; see also Becker, 2004). What can thus be called the "mindlessness claim" parallels Felin and Foss' (2011) radical interpretation of March and Simon's work as fundamentally rooted in the behaviorist tradition.

The "mindlessness claim" is also shared by major proponents of the "ostensive-performative" $(\mathrm{O}-\mathrm{P})$-also named "practice"-perspective on routines. This perspective, mainly developed in the work of M. Feldman and B. Pentland, aims to take account of agency, reflexivity, contextuality, and individual discretion in organizations-aspects that, according to its leading proponents, Simon's idea of routine seriously underestimates.

In fact, such interpretations give rise to two major reservations. First, it is rather surprising that all these views about organizational routines are attributed to an author who does not generally use the term "routine" (and even more rarely that of "organizational routine"). While this usage might be purely a matter of syntax, it might also reflect the fact that many students of organizational routines have misinterpreted Simon's concepts. Such a semantic shift would imply that Simon became "foundational" for something he did not mean or even rejected. This begs the question of what was Simon's understanding of routines and rules in organizations and their relationships with reflexivity. Second, there is something incongruous about the fact that one of the fathers of the cognitive revolution should promote a behavioristic standpoint, thereby underestimating cognitive representations and mental processes, particularly inside organizations.

We argue that the prevailing "mindlessness claim" seriously misunderstands and misrepresents Simon's approach to routine and cognition. Our main concern, however, is not merely to "do justice" to this approach or to show how it anticipated current views on routines. We attempt to show that while, from many standpoints, the "ostensive-performative" perspective on routines is quite compatible with the Simonian approach, this perspective faces serious difficulties in accounting for reflexivity and subjectivity. Our main argument is not only that Simon presents a powerful analytical framework, which overcomes such difficulties by clarifying the nature of rule-based behavior (which some call routine), but that this clarification goes far beyond purely behavioral issues of decision-making or coordination. More precisely, because Simon's approach does not separate the issue of behavioral rules from that of cognitive representations, it convincingly explains the role played by the routinized behavior in organizations. Insofar as the Simonian framework offers comprehensive and coherent solutions to contemporary debates about reflexivity, individual deliberation, and habitual action, it appears extremely modern and compelling.

Note that criticizing Simon's concept is part of broader critical attitude with regard to what some O-P proponents name the "traditional," or "capabilities" perspective on routines. " ${ }^{1}$ Traditional" is a rather generic designation, and mainly describes contributions variously inspired by the work of Nelson and Winter (1982), such as the dynamic capabilities approach (e.g., Teece and Pisano, 1994; Teece et al., 1997; Dosi et al., 2000; Zollo and Winter, 2002; Augier and Teece, 2009; Teece, 2012). Although we do not ignore potential implications of our considerations for contributions representing (or close to) "traditional" approaches to routines (see Section 5 of this article), we focus on Simon's work.

The article is structured as follows. The next section describes the "ostensive-performative" approach to routines, focusing on what its proponents view as major issues in terms of reflexivity and subjectivity. We recognize the important progress this approach has accomplished in improving understanding of rule-based behavior and its strategic dimensions. We also analyze some logical and conceptual insufficiencies and problems faced by this approach. From the perspective of this progress and these insufficiencies, we revisit Simon's account of routine, rules, and cognition as part of his decision-making theory (Section 3). We argue that this account does not reduce rule-based behavior in organizations to rigid repetitive patterns of action, but emphasizes various degrees of flexibility and actor's discretion. In Section 4, we show what solution Simon offers to the problems faced by the O-P framework. In this connection, we emphasize the fundamental role of the concept of shared frame of reference, or simplified cognitive model,

1 Parmigiani and Howard-Grenville (2011) provide a typical distinction between "practice" and "traditional/capabilities" perspectives on routine. 
in Simon's theory, and its importance in understanding behavior, reflexivity, and decisional flexibility in organizations. We argue that Simon's analysis solves the problems of normativity and coordination raised by rule-following and rule-performance. In Section 5, we test our conclusions drawn from investigation of two approaches to routines and re-examine an empirical case that was studied within the practice framework (Feldman, 2003). This reexamination shows not only that the O-P assumptions do not explain the problems posed by the case (including those that O-P proponents define as central), but also that our-Simonian-framework can solve these problems. Finally, we stress theoretical considerations drawn from our analysis of the Simonian framework and suggest links between our position and other contemporary approaches to routines. A brief conclusion follows.

\section{Ostensive-performative framework: "anti-dualism" principle}

The work of M. Feldman and B. Pentland (e.g., Pentland and Rueter, 1994; Feldman, 2000, 2003; Feldman and Pentland, 2003, 2008; Pentland and Feldman, 2005, 2008; Pentland et al., 2011; Rerup and Feldman, 2011; Miller et al., 2012; Pentland et al., 2012) is at the core of the "ostensive-performative" perspective on routines. The O-P framework appeals to a wide range of different practice theories, such as Giddens' (1984) structuration theory, the work of Bourdieu (1977), Schatzki et al. (2001), and various applications of these contributions to the analysis of contemporary organizational settings (e.g., Orlikowsky, 1992, 2007; D’Adderio, 2008). These theories are not our concern here; what are important for this article are the consequences of integrating certain notions from these theories into the O-P framework for our understanding of routine and reflexivity. From this standpoint, three main points characterize the practice approach.

(i) The O-P framework purports to bring "agency, and therefore, subjectivity and power back into the picture" (Feldman and Pentland, 2003: 95). Its ambition is to focus on improvisation, people, and "the potential in organizational routines for reflexive, agentic behavior" (Pentland and Feldman, 2005: 809). This "bringing back" is formulated in contradistinction to the "traditional/capabilities" views of routines (invoked in the introduction), including the Carnegie School framework. From the O-P standpoint, these views overemphasize stability, "diminish the role of agency or mindfulness," and "the need for organizational participants to think" (Feldman, 2003: 728) and thus underestimate "people" with their differences in perception, preferences, and interpretation. Thus, in March and Simon's approach, we read, "agency is associated with the person who writes the program but not with those who execute it" (Feldman and Pentland, 2003: 100). Therefore, the practice approach firmly sustains the "mindlessness claim."

(ii) At the core of the O-P framework is the idea that organizational routine has two parts. One part of the routine is ostensive. It is the "abstract, generalized idea of the routine," "abstract or generalized pattern," or "abstract regularities and expectations" of action (Feldman and Pentland, 2003; Pentland and Feldman, 2005, 2008). Ostensive is also viewed in terms of "understandings (embodied as well as cognitive)" (Pentland and Feldman, 2008: 241). In this regard, Pentland and Rueter (1994) invoke "cognitive structures of individuals, such as scripts" constraining and enabling behavior. The ostensive part bears the properties of a rule of action ${ }^{2}$-in accordance with Giddens' theory [see point (iii)]). The second, performative, part of routine consists of "the actual performances of the routine by specific people, at specific times, in specific places" (Feldman and Pentland, 2003: 95) so that "the performative aspect (is) the enactment" (p. 102). That is, whereas the ostensive component resembles the rule of action, the performative component is the action itself.

(iii) This aggregation of understanding (ostensiveness) and performativity into a unified concept is also justified by referring to practice theorists, especially Giddens (1984), who advocates the idea of duality of structure, essentially conceptualized in terms of rules, and agency. Correspondingly, the ostensive part of the routine appeals to structure, the performative part to agency, so that the internal dynamic of routine is a "recursive" relationship between structure and agency. In this view, associating understanding and performances overcomes the agencystructure dualism and thereby explains the mutual constitution of agency and structure within routine, in line with Giddens' general idea.

In at least five respects, the O-P framework enhanced understanding of rule-based behavior in organizations: its appeal to leading social theories; description and explanation of the flexibility of actual behavior with regard to that

2 Pentland and Rueter (1994) or Feldman and Pentland (2003) explicitly mention rules in this respect, although, in the later work, the term is often reserved for formal rules and considered as an artifact. 
prescribed by the "ostensive part"; the creation of a rich body of empirical studies; attention paid to various contextual (especially, material) factors; and stress on the role of power relationships in the routine dynamic.

As an account of reflexivity and subjectivity, however, the practice approach faces serious difficulties.

(i) O-P proponents argue the need to study the "internal dynamic" of organizational routine (Feldman, 2000) and that "the idea of constructing explanations in terms of internal structure is a basic strategy of scientific research across a wide range of disciplines" (Pentland and Feldman, 2005: 793). We share this view entirely. The problem is that, such internal structure makes its appearance as a result of definitional expansion. To "open the black box of organizational routines" (Feldman and Pentland, 2008: 302), O-P authors first aggregate two, otherwise separate, concepts, which thus become two parts of organizational routine, and then distinguish these parts to study their interaction and the "endogenous" change (or stability) that such interaction can produce. The concepts are rule (the conditional idea of action) and action. The result of the O-P aggregation is that organizational routine becomes both a rule of behavior and behavior itself. This immediately begs the question of definitional clarity. Two described phenomena are different in kind: ostensiveness appeals to cognition, performativity to behavior/action.

Not only does such expansion seem somewhat counter-intuitive, but also it leads to persistent terminological confusions within the O-P literature. While the ostensive part can be put into practice, performed, and enacted, the performative cannot because it is itself the "enactment" and "the actual performance." When O-P proponents talk about routine in their sense, i.e. containing both parts, they commonly invoke "enacted routines" or "performing an organizational routine" (Feldman and Pentland, 2003: 108; see also Rerup and Feldman, 2011). Because one cannot enact the enactment, such expressions are meaningless. This terminological tension within the integrated notion of routine is indirectly recognized by its proponents. After extensive usage of this notion, they eventually have "to distinguish between 'the routine'-often used as a shorthand to refer to the fact that an organizational task is accomplished in a stable way-and the performances that have been carried out, in the sense of a particular sequence of actions" (Pentland et al., 2012: 1504).

(ii) Contrary to its intention, the O-P framework proposes no explicit model of a reflexive actor. What lies in the human mind is reduced to the ostensive part (structure, or rule of action), so that no other mental processes can influence an agent's actions. In other words, actors become agents of this ostensive part. To use the expression of an author O-P proponents cite extensively, such actors "can only recite preexisting scripts" (Sewell, 1992: 12). That is, isolating "abstract" patterns from other cognitive structures, and at the same time integrating such patterns with behavior, is to ignore the separation between what is inside the human mind and external reality. This bears a striking similarity to behaviorism and, amazingly, can be characterized in terms of the "mindlessness claim" that the practice approach develops with regard to Simon. To specify other relationships between the human mind and action would require the rejection of the duality of routine, i.e. the aggregation of rule and action into one unit.

We do not claim that O-P proponents fail to examine cognition. In terms of integrating both parts of routine, however, this examination is problematic. Thus, Miller et al. (2012) analyze links between ostensive aspects and various forms of memory. They use only sparingly the concept of performativity, so that their considerations of reflexive actors mainly lie outside the O-P framework.

(iii) Recent developments in the O-P framework mark a more radical shift from the issues of reflexivity and real actors to actions. This evolution relies on applications of the idea of sociomateriality (mainly developed within social theories of practice) to organizations (Orlikowski, 1992, 2007; D’Adderio, 2008). Accordingly, human beings and human psychology are analytically irrelevant because such concerns "overlook the ubiquitous involvement of artefacts, such as information and communication technologies, in every real routine" (Pentland et al., 2011: 1378). As O-P proponents claim, "we break from the usual focus on actors (...) Real routines are almost never carried out by humans alone, they are carried out by sociomaterial ensembles of actants that include artefacts" (Pentland et al., 2012: 1485) so that "it is essential to have a framework that encompasses sociomaterial systems as a whole" (p. 1488). Presumably, analyzing "the interaction of human and nonhuman actants" in such a system (Pentland et al., 2011: 1369) makes it easier to incorporate both parts of routine into one model because it focuses on "the operation of this routine as a sociomaterial ensemble" (p. 1373).

This has two related consequences for the O-P framework. First, actors are replaced by "actants" in this new sociomaterial routine. Recall the statement that, "ironically, there are no people" (Feldman and Pentland, 2003: 99) in "traditional" conceptions of routine. It is even more ironic that, in the new O-P framework, people are hidden in sociomateriality. Furthermore, the focus on "ensembles" and the "system as a whole" rejects the need to analyze 
factors influencing various parts of such ensembles and systems-in contradiction with O-P's own initial ambition to provide "explanations in terms of internal structure."

The second consequence concerns the theses "that dualisms are rejected as a way of theorizing" and thereafter "that no phenomenon can be taken independently of other phenomena" (Feldman and Orlikowski, 2011: 1241, 1242). Taken at face value, such theses, imported from social theories of practice, mean that each aspect of a routine is inseparable from everything else. A corollary of this is the reinforcement of the behavioristic tendencies. One of the rejected dualisms is that between "knowledge that exists 'out there' (encoded in external objects, routines, or systems) and knowledge that exists 'in here' (encoded in human brains, bodies or communities)" (Feldman and Orlikowski, 2011: 1243). Ignoring the distinction between external and internal is the principle hallmark of radical behaviorism. This goes together with another behavioristic property that the sociomaterial approach to routines reveals: its focus on action and external situation (especially on its physical components) and the denial of the importance of mental processes. It is surprising that the O-P perspective, with its criticism of "mindlessness," becomes a framework in which actors' subjectivity and reflexivity are not distinguishable from the physical context.

(iv) O-P proponents stress non-convergent interpretations of routines. "People may differ about what makes sense to do or there may not be any story about how one performs a particular task" (Pentland and Feldman, 2005: 805). Thus, they relate Sewell's (1992) idea of "multiplicity of structures" to multiple readings of ostensive aspects of routine. Note that this parallel with Sewell's concept is not always justified, insofar as he discusses structures in terms of collective understandings (e.g., educational or religious structures), so that multiplicity means the coexistence (and possible incompatibility) of different, already shared rules of action. Among O-P proponents, the exact nature of such understandings, purely individual or shared, is somewhat ambiguous. But the main point is that "multiplicity of structures" (i.e. routines) is a typical problem of coordinating organizational behavior. It is raised by the simple fact that formal organization implies interaction between people. It is not clear what solution the O-P framework offers to this problem, in other words, how a joint action is possible and how organizations in general can exist, if each member has his/her own idea of appropriate actions.

To sum up, as an account of reflexivity and agency, the O-P approach to routines faces the following difficulties: (i) logical tensions within the expanded definition of routine; (ii) behavioristic tendencies created by the lack of distinction between processes within the human mind and external reality; (iii) risk of even more radical behaviorism resulting from the concept of "sociomaterial" routine, with its focus on action (at the expense of deliberately downgrading psychological mechanisms) and non-separation of actors from physical context; and (iv) no articulate solution to the problem of multiple interpretations of routines within the organizational context.

We will now argue, first, that Simon's theory is compatible with the O-P framework and, second, that it provides solutions to problems faced by this framework.

\section{Simon's routines, rules, and programs: mindless?}

It is striking that Simon rarely employs the term "routine." Certainly, we read of "the most routine decisions," "routine behavior," "routine positions," and even "routinized choice" (AB; March and Simon, 1958/1993). . Within the O-P framework, routine is a behaviorally oriented concept, referring to a certain kind of action or idea of action. Simon's meaning is broader, close to everyday usage: the notion applies not only to behaviors/actions but also to events, objects, or situations, that is, as a general synonym of repetition.

The following characterization, offered by March and Simon (1958/1993: 160), is perhaps closer to contemporary concepts of organizational routine. In this characterization, human responses to a perceived environment, or system of stimuli, are viewed in terms of a "continuum": "At one extreme, a stimulus evokes a response (...) that has been developed and learned at some previous time as an appropriate response for a stimulus of this class." This extreme of the continuum is called "routinized." At the other extreme, a stimulus calls for a "problem-solving" activity implying the search for an appropriate reaction, including a new response not previously learned by the decisionmaker. The routinized extreme implies a "minimum of problem-solving or other computational activity"-insofar as the recognized environmental stimuli evoke a previously elaborated and memorized set of responses.

This set of responses is called "a performance program, or simply a program" (March and Simon, 1958/1993: 162). More precisely, a program is a kind of behavioral rule (system of rules) in its most canonical sense, as a

3 On Simon's understanding of E. Stene's notion of "organizational routine," see the subsection 4.2 of this article. 
functional relation in the human mind, a specified combination of condition and action: "if condition A occurs, do B." Programs are also called production rules, decision rules, operation rules or simply rules of action, standard techniques and methods (e.g., Simon et al., 1950; March and Simon, 1958/1993; Simon, 1958; Newell and Simon, 1972; Vera and Simon, 1993). This account of rules-programs enabling organization members to stabilize mutual expectations might lead to the interpretation that, although Simon does not offer a concept of routines as "mindless repetitions" defining organizational behaviors, he assigns a very similar role to performance programs.

However, such an interpretation is ruled out by this fundamental thesis: "The term 'program' is not intended to connote complete rigidity" (March and Simon, 1958/1993: 165). Correspondingly, only in extreme cases (e.g., the assembly line) are output or methods specified to such an extent that performance of the program does not involve either search or reflexivity. Therefore, "even on routine jobs, program content (...) varies" (p. 165). The apparent contradiction between program as a stock of previously learned responses and flexibility of the program-guided behavior is avoided if we recall that the program "is not a fixed pattern of behavior but a set of ground rules (...) on the basis of which more or less rational choice can be exercised" (Simon, 1963: 743). This idea-the program is not action but rule (or set of rules) of action-is deeply rooted in Simon's investigations in the field of cognitive and social psychology. Accordingly, a program is a mental structure, which, as put by Vera and Simon (1993), enables "simple mapping" between people's view of the situation and relevant behavior. This understanding of rules-programs in cognitive terms and in line with the "if-then" schema allows for boundedly rational—and thereby deliberative—individuals, so that "the program (...) would interact with information to produce concrete behavior adapted to the situation" (Simon, 1963: 743).

Among many examined aspects of flexibility in applying rules-programs to actual situations, March and Simon (1958/1993: 169) single out decisional "discretion," which mainly appears in three cases. (i) When program performance depends on data absent from the initial stimuli, "the program will be a strategy; i.e., action will be contingent on various characteristics of the situation." Because a routine situation never implies absolute definition of future events, the resulting routinized behavior involves at least some amount of conscious reasoning. Note that strategy as a contingent program is not an accidental idea here but appeals once more to Simon's psychological research (e.g., Vera and Simon, 1993). (ii) Such discretion appears in program content and program performance, "when a program involves search activities" so that "the actual course of action depends on what is found." (iii) Finally, when a program exists "in the memory of the individual who is to apply it, having arrived there either as a result of extraorganizational training (...), or as a product of learning from experience rather than a result of formal instruction," such an application is discretionary March and Simon (1958/1993: 169-170).

After specifying these three kinds of discretion, March and Simon (1958/1993: 170) conclude that, "in all of the cases listed above, the decision process may in fact be highly routinized." Much reflexivity, intentional choice making, and decisional autonomy appear therefore in what are characterized as "highly routinized" or programgoverned activities.

This also means that, in many respects concerning individual deliberation, the practice approach, as previously presented, is not antithetical to Simon's understanding of rule-based behavior. Thus, Feldman and Pentland's (2003: 94) focus on improvisation, context, dynamics and, thereafter, on the "capability of routine to generate change, merely by its ongoing performance" clearly echoes Simon's reasoning about the strategic (or contingent) properties of programs and the radical incompleteness of formal techniques and instructions. More generally, the O-P framework is consistent with the Simonian idea that even the most routinized behavior implies choice making, interpretation, and conscious deliberation. Furthermore, the intention "not (to) separate the people who are doing the routines from the routine" (Feldman, 2000: 613) and the thesis that "routines are performed by people who think and feel and care" (Feldman, 2000: 614) are very close to March and Simon's emphasis on the decisional flexibility "of the individual who is to apply" organizational rules in real situations-without necessarily excluding rule changes.

To sum up, Simon's account of flexibility and strategic issues of rule-based behavior draws on analyzing rulesprograms in terms of specific cognitive structures. We will now examine how Simonian cognitivism, which separates rules from the actions they initiate, offers solutions to the difficulties met by the practice approach.

\section{Mental frames as mediating mechanisms}

\subsection{Two-stage decision process}

We begin with central idea of the theory of bounded rationality: "perception and cognition intervene between the decision-maker and his objective environment" (Simon, 1963: 739). Accordingly—and contrary to the claim of Felin 
and Foss-environmental stimulus is not directly related to behavioral responses, but is mediated by the individual's "internal state," especially by the "frames of reference" or "simplified models" evoked by this stimulus (March and Simon, 1958/1993)-Simon also uses labels like theories of reality, simplified maps, states of mind, classification systems, cognitive frameworks, or simply cognitive representations (e.g., Simon et al., 1950; Simon, 1952, 1955, 1963, 1991, 1996; Vera and Simon, 1993). ${ }^{4}$ By treating simplified mental models and frames as consequences of bounded rationality, Simon not only insists that individuals react to their own subjective representations of reality—and not to the reality itself-but also shows that such representations enable individuals to cope with their cognitive limits. This insistence also means that mental models offer an incomplete and inaccurate interpretation of reality.

It is remarkable that the Carnegie School often investigates mental models mediating between individuals and social structures in terms of "classification schemes" or "categorization systems." For instance, March and Simon (1958/1993) repeatedly stress the link between the classification of events and the appropriateness of rules-programs. In other words, any rule-following behavior presupposes at least some definition of the external environment by an individual. Such a definition (which is not a copy of the "objective" situation in the human's mind) is classificationremember March and Simon's definition of a program as "an appropriate response for a stimulus of this class." Classifying stimuli requires cognitive activity by individuals "so that once a situation has been assigned to a particular class the appropriate action program can be applied to it" (March and Simon, 1958/1993: 177, see also Vera and Simon, 1993). This link between two kinds of mental representations_classified events and appropriate programshas three major consequences.

The first is that decision-making turns out to be a two-stage process: first, defining the environment, including social structures, and second, evoking a rule. In the human mind, the appropriateness of the rule-program (to the extent that such a rule has already been stored in the memory) refers therefore to how the situation and the related problems are understood (first stage of decision process). Program evoking (second stage) is thus a functional relationship between classified situation and corresponding response. To say that decision-making is a two-stage process is to separate two kinds of mental structures: those responsible for specifying situation/events, and those-rules-programsrelating such specification (however, biased and incomplete) to an action.

The second consequence of introducing these two mediating mechanisms between the individual and the objective environment concerns reflexivity in rule-based behavior. This reflexivity becomes less the issue of the rule itself than that of how individuals perceive environmental stimuli before, during, and after rule-application. Even in the most complex tasks, necessitating frequent feedback on the consequences of successive actions, behavioral adjustment always depends on detecting and classifying the new stimuli, including the perceived consequences of the rule-based behavior. Such detection and classification are centerpieces of the idea of program in terms of contingent strategy, as presented in the previous section. Because categorizing events may be problematic and involves mental activity (with various degrees of consciousness), "categorizing is a basic part of thinking in any situation" (March and Simon, 1958/1993: 58). To take the extreme case of the most complete behavioral programs, it is thus still meaningful to speak of cognition and conscious intentionality. In other words, focusing on reflexivity becomes a result of this close connection between categorizing the situation and behavioral rules. Such a connection-which Levinthal and Rerup (2006: 504) call "a critical basis for the intelligence of rule-based behavior"-allows for better understanding of mindfulness and decisional flexibility.

The third consequence is that understanding rule-based behavior in terms of the two-stage decision process overcomes difficulties related to the O-P approach to routines. Recall that cognitive processes responsible for defining the situation (and corresponding to the first stage of Simon's decision process) are absent from this approach-making it unclear how agents decide to "perform." Moreover, because of the recent sociomaterial trend in the O-P approach, actors disappear within a "sociomaterial whole"-which is acting, not thinking. By contrast, it is precisely the process of thinking about the environment that characterizes Simonian decision-makers. This process, whether it precedes the application of previously learned (or newly created) rules or/and follows such application, marks individuals with reflexivity and strategic abilities.

The O-P position, which blurs the borders between external context and agent, lets the former influence the latter but allows no room for reflexivity. On the contrary, Simon strives to understand how subjective cognitive models interact with the objective environment, but do not merge with it. A situation cannot directly influence a boundedly rational individual (e.g., to perform or reject a rule-program): "it is illusory to describe a decision as 'situationally

4 On this point, see also Gavetti (2005); Koumakhov (2009, 2016); Winter (2011). 
determined' when a part of the situation that determines it is the mind of the decision-maker" (Simon, 1976: 147). It is by setting the external environment apart from decision-maker that one can introduce connecting cognitive structures, and thereafter propose a coherent account of individual reflexivity.

\subsection{Multiplicity of structures is a coordination problem}

We turn now to Sewell's "multiplicity of structures," invoked by O-P proponents to talk about incompatible interpretations of routines. Such multiplicity raises some important decision-making and social interaction. Our argument is that, first, this problem is at the heart of Simon's organization theory and, second, he offers a solution to the problem.

Formulating the problem. Simon's reasoning covers two main points. (i) The main feature of a social group (including organization, as a population of groups) is that the rationality of a group member's decision is influenced less by his/her personal preferences, but rather by beliefs about other members' choices and behavior. This is a coordination problem, which addresses uncertainty in individuals' minds about the decisions made by other individuals. As Simon puts it, "each of the coordinated individuals sets for himself a criterion of choice that makes his own behavior dependent upon the behavior of others" ( $A B$ : p. 178). In this account, resolving coordination problems is a major function of formal organizations. (ii) The complexity of this issue of coordination in organizational settings is especially due to the trivial fact that organizations are not simple groups, but combinations of various groups. Yet each group possesses its own shared set of expectations. Since such sets may not be concordant, the question of how different group members adopt common (or, at least, compatible) expectations should be a major concern of organization theory (Simon, 1952).

"Multiplicity of structures" typifies a coordination problem of this kind. First, to apply a behavioral rule, organization members need concordant understandings of the rule. Second, the coexistence of structures in Sewell's sense translates the coexistence of different groups within the organization. For instance, religious, educational, or professional structures are, in that sense, shared interpretations of relevant behavior and translate belonging to the different religious, educational, or professional groups. Coordinating behavior with other members' behaviors is thus complicated by multiplicity of the shared interpretations.

Solving the problem. The solution is to address the issue of mental representations in terms of social interaction. In Simon's account, when individuals become members of a group (organization), they accept cognitive models/ frames supplied by the group. Such common models do influence subjective perceptions and interpretations. Insofar as individual cognitive models are shared, they turn out to be social constructions. Simon's examples of the shared models include bureaucrats' value systems (Simon, 1967) or bankers' and entrepreneurs' different understandings of the same situation (Sarasvathy et al., 1998).

Changing the analytical level—from individual to social/organizational—implies the appearance of the normative dimension in cognitive representations. To the extent that social approval/pressure sustains a set of organizational rules (programs), such a set relies on a value system and possesses moral characteristics. One may appeal to the normative nature of organizational rules as a solution to the problem of coordination. It is remarkable that in one of Simon's rare discussions of the term "organizational routine" (with regard to E. Stene's notion), he defines the latter as "accepted or approved practices" ( $A B: 100)$, that is, as grounded in social convention. "Organizational routine," interpreted so, is similar to the behavioral mores and thereby implies a normative vision of interaction. Such normativity—with social approval sustaining routinized behavior ${ }^{5}$ - helps organizational members to stabilize mutual expectations. In this view, a routine would be legitimized (and thereafter obtain common meaning) by its conventional character-unlike purely individual behavioral habits.

This solution alone-normativity of behavior-is unsatisfying. To take the example of "multiple structures," each understanding of rule-based behavior may be normative insofar as it is already shared within the organizational subgroup and relies on the subgroup's approval. Because such understanding (of what action is "right") is thus a legitimate viewpoint, multiple understandings, with multiple groups claiming legitimacy, often provide opposing normative viewpoints. Moreover, it is not unawareness of behavioral norms that creates the problem of coordination and choice. An organization member might know perfectly well which behavioral norms are adopted within different organizational subgroups in the same circumstances. However, each subgroup has its specific comprehension of such

5 This aligns with Nelson and Winter's (1982) idea of routines as "truces." 
circumstances. The problem of coordinated actions turns out to be much broader than merely the issue of (expectations of) actions. To select the "right" organizational rule from the available stock of rules, organization members need a common vision of the situation.

The Simonian solution is this. Common representations, with their normative aspects, are not reduced to behavioral rules (organizational programs), but also include perceptual mechanisms defining situations for group members. Recall that "classificatory schemes" are mental structures characterizing the first stage of the decision process, which precedes the second stage-evoking the "appropriate" rule from memory. This functional dependence of behavioral rules upon classification of stimuli is important for the issue of coordination. Insofar as individuals adopt the same perceptual and classificatory schemes, they are able to reach common evaluation of the situation (first stage of the decision process). Drawing on such evaluation, individuals can jointly find corresponding rules (second stage of the decision process). In other words, it is because the "classificatory schemes" become shared within the organization that the behavioral rules also become jointly accepted and normative.

One important aspect of this solution is that the adoption of these common cognitive constructions is what actually specifies a social group itself. This thesis—shared mental models are distinctive properties of corresponding groups-is at the heart of Simon's (Simon, 1952, 1993, 2001; March and Simon, 1958/1993) idea of social/organizational identification. ${ }^{6}$ To identify with a group is thus to internalize normative representations. Considered in this manner, it is social/organizational identification that allows for coordinated behavior.

Note that, in Simon's view, common understanding of the situation is not necessarily given between organizational subgroups. Most organization members tend to share cognitive frames either with working groups that interact face-to-face or with professional groups-and therefore accept a subgroup's goals, knowledge system, and set of beliefs more easily. The problem of rule-following becomes the problem of organizational identification(s).

To summarize, the practice-theoretical term "multiplicity of structures" appeals to the multiplicity of social belongings and to interaction (including confrontation) between normative mental constructions. Because the problem of coordination resulting from such multiplicity cannot be solved on purely behavioral grounds, Simon's appeal to both individual and social cognition offers an interesting and forceful solution.

\section{Empirical implications: the housing division case}

To illustrate the difficulties of the practice approach empirically, and to consider how applying the Simonian perspective can provide appropriate solutions, we turn to the case presented and analyzed by Feldman (2003). The case is rich in material elements and concerns a new "budget routine" in the housing division of a state university. The practice approach, here called the "performative perspective," supplies a theoretical framework for the case.

The purpose of the "performative perspective" is thus to suggest "a larger role for agency" and to stress "the role that performances, or actions people take that enact the abstract idea of an organizational routine, play in what people understand they are doing when they enact organizational routines (...) The dynamic is a recursive relationship between understanding and performances, as described in practice or structuration theory terms" (Feldman, 2003: 728). We therefore find all the basic elements of the practice approach: "the abstract idea" of routine (named "ostensive part" in later O-P work), the two-part dynamic, insistence on agency, and corresponding theoretical references. The key assumption is that performances/actions initiate major causal relations with other elements of the O-P framework: "the relevant performances help people construct an understanding of how the organization operates, which helps them determine what actions it makes sense to take in a specific routine. The actions people take in a specific routine can, in turn, be relevant performances that contribute to creating understandings about how the organization operates" (p. 729).

As an illustration, the study describes the attempts to change the budget process in the housing division, in particular in its three main departments. Each department has supervisors who represent it at the budget meeting. The housing division operates 12 student residences. Because each department has a manager responsible for the residence, the traditional budget process is that residence managers submit 36 separate lists of projects. The "new subroutine" is for each residence to submit a single list of budget projects agreed jointly by the three department managers (and, hence, to reduce the total number of lists to 12). The "new subroutine" was supposed to "emphasize"

6 Koumakhov (2016) examines this idea in some detail. 
the general idea of organizational change that supervisors wanted to initiate at residence level and, more precisely, three features: cooperation, empowerment, and sense of responsibility. After 4 years of effort, "nothing worked" (Feldman, 2003: 733) because performances "enacted" the opposite vision: (i) competitive, (ii) hierarchical, and (iii) without sense of responsibility. Correspondingly:

- "the supervisors enacted competition with one another in the budget routine" (p. 746-747) and, in most cases, rivalry prevented managers from acting as a team;

- at residence level, managers followed the traditional distribution of authority, which supported "Building directors" (representing only one department) and encouraged a "hierarchical" interpretation of the organization;

- supervisory performances coming "from outside as well inside the specific" budget routine contradicted the development of the "sense of responsibility" at the residence level, and created corresponding understandings.

In other words, the general understanding of organization, as represented by features (i)-(iii), is a function of performances. This analysis raises several problems. First of all, definitional issues are rather problematic. Confusing O-P terminology (invoked in Section 2) is coupled with calling the new, or desired, course of budget action "routine," or being "of a routine nature," or "subroutine." Such terminology is debatable because this course is not of a sort that the housing division practiced before. Insofar as "nothing worked," most of these new performances never became "routine" or even occurred.

But the main problem in using the "performative perspective" is this. If "relevant" performances were totally inconsistent with declared intentions, why did such surprising performances, whether initiated by supervisors or residence managers, occur? First, while the new budget action was supposed to "emphasize" the general vision of organization and organizational change (promoting cooperation, empowerment, and responsibility), the proposed analysis does not explain why participants behave contrary to these general principles. Second, the described performances are totally disconnected from the initial understanding of the new specific budget "subroutine" itself. That is, there is no causal link between the action and "the abstract idea of organizational routine" that such action was supposed to "enact." It is hard to see how actions like competitive behavior, reproducing hierarchy, and denying responsibility result from the idea of the new budget process.

This has two implications for applying the O-P framework. One is that, contrary to proponents' claims, it cannot describe "the way that the participants in the routine made sense of the budget routine" (Feldman, 2003: 746). The framework allows us to see participants acting, not the reasons for such actions. This is consistent with the O-P account, which, instead of stating interactions between performances, the human mind (where "making sense" takes place), and the context, focuses on the direct relationship between performances and context. In this account of the budget process, relevant performances seem to be either an independent variable (i.e. arising from nowhere) or, at best, contextually defined. This leaves agents' reflexivity and, to a substantial extent, subjectivity outside the "performative perspective." The second implication is that the disconnection between abstract understanding of the budget "routine" and performances makes it difficult to view them as two parts of the same routine-so that their presumed dynamic cannot be empirically studied.

Let us consider the case from the Simonian perspective. To begin with definitional issues, it would be more appropriate to talk about attempts to perform newly conceived behavioral rules (and not about new budget "subroutine" action). Such rules do not seem to be a result of trial-and-error activities leading to a method, which would implement the broader vision (cooperation, power, and responsibility) more or less efficiently. These rules (and thereafter behavior they were supposed to generate) were not actually routinized because they had not been stored in participants' minds as programs anchoring actions to recurrently experienced situations (including consequences of the application of such programs).

Considering the main problem-where do the intriguing performances come from-we turn to the empirical material of the case and more particularly to the three main principles of the declared organizational change: cooperation, empowerment, and sense of responsibility.

- Concerning cooperation, the subjects talk about a tradition of "narrow interests and competition," "territorial responses," and "everyone (...) worrying about his or her own area and not about the building as a whole" (Feldman, 2003: 737). We have strong reasons to think that the prevailing understanding of supervisors was rather "competitive" and not "cooperative." Whatever they claim officially, it was this kind of mental representation that continued to generate rivalry and to "inhibit cooperation" in the budget process. 
- Concerning empowerment, the Building directors' influence on other residence managers is similarly rooted in the well-established cognitive frames. As one of them justifies her continuing leadership, "part of that makes sense because the Building director is the most educated, the most used to doing that" (p. 741, emphasis submitted). What is rationalized here is routinized behavior resulting from the previous mental representation prioritizing "hierarchy." Because the actors involved did not actually change these ready-made representations, they did not want to change such behavior. Regardless of declarations, "hierarchical” principles (including related behavioral rules) dominate participants' mental representations and trigger relevant performances such that "a team of equals did not emerge" (p. 742). That is, the "hierarchical" understanding of the organization was not communicated from somewhere outside-it had been already stored in the heads of the actors concerned with the "budget routine."

- Finally, the supervisors had a particular sense of their subordinates' responsibility, to the extent that they never presumed that the residence "managers should have control over what happens in the buildings or with the budget for the building" (p. 743). Moreover, the usual practice was that supervisors regularly changed projects without consulting lower-level management. The empirical data clearly show that they had no intention of rejecting this routinized practice. As one of supervisors put it, "we as the senior managers have the right to set priorities in certain areas (...) we might see a bigger picture" (p. 744). Again, actions contradicting the development of the sense of responsibility were grounded in corresponding representations (including the rule of unilateral project change) stored in the minds of those in charge of the budget process.

The key conclusion is thus not that supervisory and lower management performances reinforced understanding based on competition, the traditional distribution of authority, and lack of direct responsibility. They probably didof course, not directly, but by assessing the consequences of such performances through participants' mental models. Our main point, however, is that these actions themselves were deeply rooted in (and therefore totally aligned with) the well-established set of representations promoting competition, traditional hierarchy, and lack of responsibility.

If we consider that participants were sincere about their intention to change the budget "subroutine" and organizational structures, i.e., if we accept the claim that "these same people were not adverse to change" (Feldman, 2003: 746), this would mean they had contradictory representations-with the idea of change being inconsistent with the dominant cognitive framework (how people perceived problems and related behavioral solutions). That is why such a framework did not activate the new "subroutine" action. Instead, what was activated as appropriate behavior was performances, including previous budget "(sub)routine" actions-in line with the dominant cognitive framework. The change was not "enacted" in practice, because on the representational level, it was marginalized and conflicted with basic values, intentions, and actions stored in participants' memory.

\section{Conceptual issues}

As the previous examination shows, we share the Simonian view of routine and rules in organizations. We will now emphasize the theoretical issues resulting from our examination and establish connections with other positions on organizational routines.

i. In accordance with Simon's standpoint, we consider "routinized" behavior to be action (sequence of actions) generated by repetitive application of "if-then" rules, sometimes called programs. Our view thus coincides with Egidi's position (as stated in Cohen et al., 1996; see also Egidi, 1996), who also follows Simon in this regard. Like Egidi, we could have labeled these rules-programs "routines"; our major reservation about such labeling comes from concern about maintaining consistency with the conventional broader usage of this term by social scientists in general (e.g., Merton, 1949) and the Carnegie group in particular. More important than this terminological issue is Egidi's insistence that actual routinized behaviors and rules initiating such behaviors are distinct categories appealing to different realities.

ii. We consider rules-programs, or behavioral rules, as components of cognitive structures (models or frameworks). Functionally, cognitive structures consist of two major kinds of representations. The function of the first representation is to translate the objective environment into a definition of the situation. Such translation is the perceptual process. The second functional representation establishes connections between this definition and corresponding responses already stored in the mind (e.g., as a result of trial-and-error reactions to recurrent situations). This second representation is a set of behavioral rules. Both kinds of representations are hierarchical, so 
that in complex situations, more detailed representations of both kinds are established to deal with understanding external stimuli and finding adequate behavioral rules in the memory.

iii. It follows from this Simonian-functional-perspective on mental representations that routinized behaviors are not the product of direct confrontation between individual and situation, but guided by (functionally dependent upon) mental structures called rules (which are themselves activated by—or functionally dependent upon—other mental structures dealing with understanding the situation). Mental structures trigger the application of rulesprograms to the actual situation, the adaptation of rules to new problems, the reconfiguration of a set of rules, or the search for new rules.

iv. These causal connections, situation-definition of the situation-adequate behavioral rules-actual behavior, are not deterministic. For example, a repeated situation may not be understood in the same way as in the past, or not be recognized at all (and representation itself is never an unbiased image of the environment); after its definition, the actor may not rapidly find appropriate action rules; applying the rules (execution of action) requires interaction with environment. This absence of determinism is general. As Simon (1996: 429) puts it, "perhaps an exception can be made for cases where the situation is so transparent that it is obvious what the actor knows that is, actually aware of or can calculate (...), but even in such simple situations the computational processes of an actor cannot be taken for granted." In other words, each causal connection presupposes thinking activities, including adaptation to the newly perceived stimuli.

v. It is because Simon's theory clearly separates external settings (including social structures) from cognitive structures that people use to make sense of these settings, that it can describe and explain how actions are caused by people's (subjective and shared) intentions and interpretations. And it is because the same theory clearly separates rules of behavior (as components of cognitive structures) from real-life behavior that it helps us to examine decisional flexibility and strategic reasoning.

vi. This kind of cognitivism, which distinguishes rules from routinized actions, but also perceiving the situation from rule-evoking, enables to solve coordination problem in organizational settings. Coordination of mutual expectations with regard to the choice and application of organizational rules is thus grounded in shared mental representations, especially in normative understandings (perceptions) of the situation.

Our-Simonian-approach to rules and reflexivity offers promising connections with contemporary approaches to routines. As previously discussed, this approach complements the O-P perspective well, and is very close to Egidi's position. Interesting rapprochements may be further explored with the dynamic capabilities framework (Teece and Pisano, 1994; Teece, 2007, 2012; Augier and Teece, 2009), the work relating routines to mental structures and problem-solving (Marengo et al., 2000; Dosi et al., 2011; Winter, 2013; Cohen et al., 2014; Marengo, 2015), the routines-as-propensities view (Hodgson, 2003; Hodgson and Knudsen, 2004, 2006), and contributions on behavioral strategies (Gavetti et al., 2007). Although the Carnegie School is, to differing degrees, the foundation for these approaches, our examination suggests that a more complete integration of Simon's account of rule-based behavior, and especially of its cognitive, normative, and strategic aspects, would be an interesting topic to research. It also seems important to relate the "microfoundations-of-routines" project (Foss et al., 2012) and research on the neurological foundations of decision processes in social settings (e.g., Laureiro-Martinez et al., 2010) to Simon's cognitivism.

Let us discuss two of these examples. One concerns the dynamic capabilities approach, which emphasizes discovering and seizing opportunities, and reconfiguring tangible and intangible assets. We can single out three major relationships with Simon's theory.

i. The insistence on the ability to discover opportunities-including "scanning, interpretative, and creative processes" (Teece, 2007) - is coupled with the claim that distinguishing between dynamic capabilities and ad hoc problem solving may be a "false dichotomy" (Teece, 2012). Such a coupling is consistent with the idea of ruleprogram as strategy in March and Simon's sense; that is, implying goal redefinition, decisional discretion, and search process to the extent that performing such programs depends on information not available in many initial stimuli.

ii. With regard to seizing opportunities and reconfiguring assets, exponents of dynamic capabilities explicitly appeal to Simon's concept of organizational identification, especially when they invoke "adherence to innovation and efficiency as important goals" (Teece, 2007: 1334). Furthermore, Augier and Teece (2009) relate Simon’s tenet 
about strong identification with subgroups to "reference points for more efficient decision making" (p. 417) in relatively decomposed organizational structures-such decomposability being viewed as an important microfoundation for reconfiguring knowledge and tangible assets (Teece, 2007). Note that this tenet might have further implications for the dynamic capabilities approach. This views the issue of coordination (of activities and assets) as central, especially in the context of incomplete information. Remember that, in Simon's account, the coordination problem is also a major problem for an organization, and concerns uncertainty in the decisionmaking process. ${ }^{7}$ Because, in this account, organization is a combination of interacting subgroups, its structures and corresponding decisions rely on the interplay between extra- and intra-organizational identifications. This allows us to consider "the concept of dynamic capabilities as a coordinative management process" (Teece and Pisano, 1994) in terms of interacting identifications.

iii. The dynamic capabilities approach also stresses the role of firm-specific assets that are difficult to imitate. Fundamentally, Simon discusses the same phenomena when he examines the cognitive model commonly adopted by organizational members, but also the corresponding subgroup models and their combinations in a given organizational setting-sometimes conflicting with each other and/or with the model of the focus organization. He thereby reveals the sources of organizational uniqueness defined by such models (each with its own system of "as-if" rules and perceptual structures) and their specific configurations.

To give a second example of connections to investigate, we briefly turn to Zollo's understanding of the "microfoundations-of-routines" project (in Foss et al., 2012). Among key features that, according to Zollo, such a project should retain, five appear important for our concern: (i) epistemological considerations such as the holism-individualism issue; (ii) multidisciplinary approaches; (iii) a more complete account of human psychology to overcome behavioral "bias"; (iv) investigation of "deliberative cognitive efforts," "stable, but not fixed traits of organization," and intentionality of change; $(\mathrm{v})$ in addition to routines, inclusion of cognitive representations, strategies, powers, and cultural components of change in the subject matter of "microfoundations."

We shall see now how we can read Simon through these lenses.

i. From the epistemological and methodological perspective, Simon clearly distinguishes agency from social structures and introduces mediatory mechanisms between them: cognitive representations. Because reflexivity is thus related to interaction between rational thinking (in the general sense of means-ends compatibility) and social constraints, Simon's position views humans neither as asocial individuals nor as products of society.

ii. Although it is a commonplace that Simon is a polymath, this point is probably underestimated with regard to his analysis of routinized behavior and reflexivity. To take one example, Simon frames the problem of organizational rules as coordination mechanisms in sociopsychological or sociological terms (when he considers this coordination as an issue of interaction between various social identifications) and in terms of cognitive psychology (when he considers it as an issue of interaction between different perceptual and classificatory systems). More generally, Simon's analysis clearly articulates views from economics, various fields of psychology, political, computer, and many other sciences, and thus is an archetype of the multidisciplinary approach Zollo suggests we develop.

iii. Simon's account of routine and reflexivity is thus psychologically grounded. Moreover, he develops the concept of rules-programs within the framework of very anti-behavioristic theory. Programs are mental structures, which are anchored with (i.e., functionally dependent on) other mental structures, especially those responsible for perception and classification of the situation. Thus, behavioral rules alone cannot sustain human action. The most routinized conduct is always preceded by the two-stage process (categorizing the situation and evoking anchored behavioral rules) on the level of cognitive representations. This also applies to social interaction, since we cannot address coordinating actions from the behavioral perspective only, but must also consider that of shared cognitive frameworks. There is thus no behavioral "bias" in Simon's approach.

7 This issue of coordination is also central in Argote and Ren's (2012) explanation of dynamic capabilities in terms of a "transactive memory system." There is no room to analyze in detail this connection with Simon here, but even from a more general perspective, such systems, including "common codes of communications" and trust in expert knowledge, share major characteristics of common mental models conceptualized by Simon as knowledge and belief systems. 
iv. Because Simon's theory implies these two-stage mechanisms, which distinguish perceiving the environment from rule-evoking, it focuses on people's inherent reflexivity. Whether the definition of the situation leads to an evocation of already memorized behavioral rules as routinized responses (when the situation is easily recognized) or to solving new problems (e.g., the discovery of solutions to be routinized), it is itself a more or less (usually more than less) rational activity. In other words, the cognitive process of classifying situations is a strong sign of intentional reasoning. Similarly, since the resulting subjective representations are always partial, Simon's "routinized responses to perceptual conditions" are not fixed behavioral patterns. Such routines are "contingent programs" acting together with new information (therefore involving, once more, mental—and largely rational—processes to define the situation) and injecting a strong dose of decisional flexibility (or "deliberative cognitive efforts" to return to Zollo's project).

v. Since the previous points have already considered the central role played by cognitive representations and strategies in Simon's theory, we briefly turn to two other aspects invoked with regard to the "microfoundations" project: power and culture. The fact that Simon frequently distinguishes inherently incomplete (and often irrelevant) formal instructions, charts, and blueprints from "informal supplement" (e.g., AB; March and Simon 1958/ 1993) - i.e., actual methods and conventional regularities used by the "individual who is to apply" rules-programs-appeals to the important dimension of his theory related to power relationships. We have also observed that cultural or ideational influence, with corresponding normative considerations, becomes a key element of cognitive representations, insofar as they are viewed within the context of social groups, especially formal organizations. Such shared representations rely on social approval and include collective values or, in other words, the moral dimension of coordinated decisions.

\section{Conclusion}

We have examined the O-P or practice approach to organizational routines and found some difficulties it encounters when dealing with the issues of reflexivity, subjectivity, and social interaction. The proponents of this approach offer a unified concept of routine, which combines behavioral rule and behavior itself. This creates conceptual problems with fulfilling the very purpose of the O-P framework, which is to explore how the dynamic of agency and structure influences deliberation and subjectivity. The dualistic concept of routine leaves unspecified some of the main foundations of human reasoning and ignores the difference between mental world and external reality. These behavioristic tendencies-which counter the aims of the O-P program-are reinforced by the recent "sociomaterial" trend. We also observed that the practice approach does not provide an answer to the question of "multiplicity of structures," i.e., the problem of different understandings of a routine by organization members.

In connection with this, we have explored Simon's idea of "routinized" behavior and found that it involves a great deal of flexibility and strategic thinking. The assumption of bounded rationality implies that actual behavior in organizations draws both on conscious reasoning and on a set of socially expected rules of action, sometimes investigated under the label of programs. We do not find evidence that this idea assimilates rule-based behavior to "mindless repetition," as is often asserted in the large body of literature on organizational routines.

More importantly, Simon offers powerful solutions to problems faced by the O-P framework. To show this, we have addressed another consequence of bounded rationality, the fact that people create incomplete and inaccurate cognitive models, or representations of the world. As mechanisms of mediation between an individual and the environment, these representations imply that rule-governed action draws on two mental functional relationships: perceiving the situation and choosing a behavioral rule anchored in this "perceptual condition." The link between the external situation and the situation represented in human mind is rarely an entirely obvious relationship, so that even when this choice is almost automatic, individual reflexivity and intentionality are involved in the decision and action processes.

Because the validity of a theory is ultimately an empirical question, we have investigated a case study originally presented within the practice framework. We showed problems that the framework encounters in analyzing the case, and how applying Simonian assumptions led to more satisfactory explanations for these problems.

In the light of these considerations, we endorsed the Simonian viewpoint on reflexivity, emphasized its theoretical implications, and established links with other approaches to routines. 
Simon insists that organizations provide their members with shared models of reality and thereby influence individual perceptions, rule-evoking and rule-application. Because mental representation contains beliefs (including value judgments) and knowledge systems, social—not only individual—cognition intervenes in rule-based behavior. We showed that such cognitivism addresses the question of the "multiplicity of structures" applied to routines and examined this question as a coordination problem. Viewed in this way, shared mental models offer cognitive and normative foundations for coordination and enable to avoid undecidability with regard to the choice and application of organizational rules.

\section{Acknowledgements}

Various parts and versions of this article were presented at the AOM Annual Conference and PROS Symposium. We are thankful to Davide Nicolini, Brian Pentland, and other participants at these meetings. We also wish to thank Mark Holdsworth, John Latsis, and two referees.

\section{References}

Argote, L. and Y. Ren (2012), 'Transactive memory systems: a microfoundation of dynamic capabilities,' Journal of Management Studies, 49, 1375-1382.

Augier, M. and D. J. Teece (2009), 'Dynamic capabilities and the role of managers in business strategy and economic performance,' Organization Science, 20, 410-421.

Becker, M. C. (2004), 'Organizational routines: a review of the literature,' Industrial and Corporate Change, 13, 643-677.

Becker, M. C., N. Lazaric, R. R. Nelson and S. G. Winter (2005), 'Applying organizational routines in understanding organizational change,' Industrial and Corporate Change, 14, 775-791.

Bourdieu, P. (1977), Outline of a Theory of Practice. Cambridge University Press: Cambridge.

Cohen, M. D. (2007), 'Reading Dewey: reflections on the study of routine,' Organization Studies, 28, 773-786.

Cohen, M. D., R. Burkhart, G. Dosi, M. Egidi, L. Marengo, M. Warglien and S. Winter (1996), 'Routines and other recurring action patterns of organizations: contemporary research issues,' Industrial and Corporate Change, 5, 653-698.

Cohen, M. D., D. A. Levinthal and M. Warglien (2014), 'Collective performance: modeling the interaction of habit-based actions,' Industrial and Corporate Change, 23, 329-360.

D'Adderio, L. (2008), 'The performativity of routines: theorising the influence of artefacts and distributed agencies on routines dynamics,' Research Policy, 37, 769-789.

Dosi, G., M. Faillo, L. Marengo and D. Moschella (2011), 'Toward formal representations of search processes and routines in organizational problem solving: an assessment of the state-of-the-art,' Seoul Journal of Economics, 24, 247-286.

Dosi, G., R. R. Nelson and S. G. Winter (eds) (2000), The Nature and Dynamics of Organisational Capabilities. Oxford University Press: Oxford.

Egidi, M. (1996), 'Routines, hierarchies of problems, procedural behaviour: some evidence from experiments,' in K. J. Arrow, E. Colombato, M. Perlman and C. Schmidt (eds), The Rational Foundations of Economic Behaviour. St. Martin's Press: New York, NY and Macmillan: London, pp. 303-333.

Feldman, M. S. (2000), 'Organizational routines as a source of continuous change,' Organization Science, 11, 611-629.

Feldman, M. S. (2003), 'A performative perspective on stability and change in organizational routines,' Industrial and Corporate Change, 12, 727-752.

Feldman, M. S. and W. J. Orlikowski (2011), 'Theorizing practice and practicing theory,' Organization Science, 22, $1240-1253$.

Feldman, M. S. and B. T. Pentland (2003), 'Reconceptualizing organizational routines as a source of flexibility and change,' Administrative Science Quarterly, 48, 94-118.

Feldman, M. S. and B. T. Pentland (2008), 'Routine dynamics,' in D. Barry and H. Hansen (eds), The SAGE Handbook of New Approaches in Management and Organization. SAGE Publications Ltd: London, pp. 302-315.

Felin, T. and N. J. Foss (2011), 'The endogeneous origins of experience, routines, and organizational capabilities: the poverty of stimulus,' Journal of Institutional Economics, 7, 231-256.

Felin, T., N. J. Foss, K. H. Heimeriks and T. L. Madsen (2012), 'Microfoundations of routines and capabilities: individuals, processes, and structures,' Journal of Management Studies, 49, 1351-1374.

Foss, N. J., K. H. Heimeriks, S. G. Winter and M. Zollo (2012), 'A Hegelian dialogue on the micro-foundations of organizational routines and capabilities,' European Management Review, 9, 173-197.

Gavetti, G. (2005), 'Cognition and hierarchy: rethinking the microfoundations of capabilities' development,' Organization Science, $16,599-617$.

Gavetti, G., D. Levinthal and W. Ocasio (2007), 'Neo-Carnegie: the Carnegie School's past, present, and reconstructing for the future,' Organization Science, 18, 523-536. 
Giddens, A. (1984), The Constitution of Society: Outline of The Theory of Structuration. University of California Press: Berkley and Los Angeles.

Greve, H. R. (2007), 'Exploration and exploitation in product innovation,' Industrial and Corporate Change, 16, $945-975$.

Hodgson, G. M. (2003), 'The mystery of the routine: the Darwinian destiny of an evolutionary theory of economic change,' Revue Economique, 54, 355-384.

Hodgson, G. M. and T. Knudsen (2004), 'The firm as an interactor: firms as vehicles for habits and routines,' Journal of Evolutionary Economics, 14, 281-307.

Hodgson, G. M. and T. Knudsen (2006), 'Dismantling Lamarckism: why descriptions of socio-economic evolution as Lamarckian are misleading,' Journal of Evolutionary Economics, 16, 343-366.

Howard-Grenville, J. (2005), 'The persistence of flexible organizational routines: the role of agency and organizational context,' Organization Science, 16, 618-636.

Koumakhov, R. (2009), 'Conventions in Herbert Simon's theory of bounded rationality,' Journal of Economic Psychology, 30, 293-306.

Koumakhov, R. (2016), 'Simon on social identification: two connections with bounded rationality,' in R. Frantz and L. Marsh (eds), Minds, Models and Milieux: Commemorating the Centennial of the Birth of Herbert Simon. UK: Palgrave Macmillan, pp. 209-226.

Laureiro-Martinez, D., S. Brusoni and M. Zollo. (2010), 'The neuroscientific foundations of the exploration-exploitation dilemma,' Journal of Neuroscience, Psychology, and Economics, 3, 95-115.

Lazaric, N. (2011), 'Organizational routines and cognition: an introduction to empirical and analytical contributions,' Journal of Institutional Economics, 7, 147-156.

Levinthal, D. and C. Rerup. (2006), 'Crossing and apparent chasm: bridging mindful and less-mindful perspectives on organizational learning,' Organization Science, 17, 503-514.

March, J. G. and H. A. Simon. (1958/1993), Organizations, 2nd edn. Basil Blackwell: Cambridge, UK.

Marengo, L. (2015), 'Representation, search, and the evolution of routines in problem solving,' Industrial and Corporate Change, 24, 951-980.

Marengo, L., G. Dosi, P. Legrenzi and C. Pasquali. (2000), 'The structure of problem-solving knowledge and the structure of organizations,' Industrial and Corporate Change, 9, 757-788.

Merton, R. K. (1949), Social Theory and Social Structure. The Free Press: Glencoe, IL.

Miller, K. D., B. T. Pentland and S. Choi. (2012), 'Dynamics of performing and remembering organizational routines,' Journal of Management Studies, 49, 1536-1558.

Nelson, R. R. and S. G. Winter. (1982), An Evolutionary Theory of Economic Change, Harvard University Press: Cambridge, MA.

Newell, A. and H. A. Simon. (1972), Human Problem Solving. Prentice-Hall: Englewood Cliffs, NJ.

Orlikowski, W. J. (1992), 'The duality of technology: rethinking the concept of technology in organizations,' Organization Science, $3,398-427$.

Orlikowski, W. J. (2007), 'Sociomaterial practices: exploring technology at work,' Organization Studies, 28, 1435-1448.

Parmigiani, A. and J. Howard-Grenville. (2011), 'Routines revisited: exploring the capabilities and practice perspectives,' Academy of Management Annals, 5, 413-453.

Pentland, B. T. and M. S. Feldman. (2005), 'Organizational routines as a unit of analysis,' Industrial and Corporate Change, 14, 793-815.

Pentland, B. T. and M. S. Feldman. (2008), 'Designing routines: on the folly of designing artifacts, while hoping for patterns of action,' Information and Organization, 18, 235-250.

Pentland, B. T., M. S. Feldman, M. C. Becker and P. Liu. (2012), 'Dynamics of organizational routines: a generative model,' Journal of Management Studies, 49, 1484-1508.

Pentland, B. T., T. Haerem and D. Hillison. (2011), 'The (n)ever changing world: stability and change in organizational routines,' Organization Science, 22, 1369-1383.

Pentland, B. T. and H. H. Rueter. (1994), 'Organizational routines as grammars of action,' Administrative Science Quarterly, 39, 484-510.

Reynaud, B. (2005), 'The void at the heart of rules: routines in the context of rule-following. The case of the Paris metro workshop,' Industrial and Corporate Change, 14, 847-871.

Sarasvathy, D. K., H. A. Simon and L. Lave. (1998), 'Perceiving and managing business risks: differences between entrepreneurs and bankers,' Journal of Economic Behavior and Organization, 33, 207-225.

Schatzki, T. R., K. Knorr-Cetina and von E. Savigny (eds) (2001), The Practice Turn in Contemporary Theory. Routledge: London.

Sewell, Jr., W.H. (1992), 'A Theory of Structure: Duality, Agency, and Transformation,' American Journal of Sociology, 98, 1-29.

Simon, H. A. (1947/1997), Administrative Behavior, 4th edn. Free Press: New York, NY.

Simon, H. A. (1952), 'Comments on the theory of organizations,' American Political Science Review, 46, 1130-1139.

Simon, H. A. (1955), 'Recent advances in organization theory,' in S. K. Bailey (ed.), Research Frontiers in Politics and Government. The Brookings Institution: Washington, DC, pp. 23-44. 
Simon, H. A. (1958), 'The role of expectations in an adaptive or behavioristic model,' in M. J. Bowman (ed.), Expectations, Uncertainty, and Business Behavior. Social Science Research Council: New York, NY, pp. 49-58.

Simon, H. A. (1963), Economics and psychology,' in S. Koch (ed.), Psychology: A Study of A Science. McGraw Hill: New York, NY, Vol. 6, pp. 685-723.

Simon, H. A. (1967), 'The changing theory and changing practice of public administration,' in I. de Sola Pool (ed.), Contemporary Political Science: Toward Empirical Theory. McGraw-Hill: New York, pp. 86-120.

Simon, H. A. (1976), 'From substantive to procedural rationality,' in S. J. Latsis (ed.), Method and Appraisal in Economics. Cambridge University Press: New York, NY, pp. 129-148.

Simon, H. A. (1991), 'Cognitive architectures and rational analysis: comment,' in K. VahnLehn (ed.), Architecture for Intelligence. Erlbaum: Hillsdale, NJ, pp. 25-39.

Simon, H. A. (1993), 'Strategy and organizational evolution,' Strategic Management Journal, 14 (S2),131-142.

Simon, H. A. (1996), 'The patterned matter that is mind,' in D. M. Steier and T. M. Mitchell (eds), Mind Matters: A Tribute to Allen Newell. Erlbaum Associates: Mahwah, NJ, pp. 407-431.

Simon, H. A. (2001), 'Rationality in society,' in N. Smelser and P. Baltes (eds), International Encyclopedia of the Social and Behavioral Sciences, Vol. 19. Elsevier Science: Oxford, pp. 12782-12786.

Simon, H. A., V. A. Thompson and D. W. Smithburg. (1950), Public Administration. Alfred A. Knopf: New York, NY.

Teece, D. J. (2007), 'Explicating dynamic capabilities: the nature and microfoundations of (sustainable) enterprise performance,' Strategic Management Journal, 28, 1319-1350.

Teece, D. J. (2012), 'Dynamic capabilities: routines versus entrepreneurial action,' Journal of Management Studies, 49, $1395-1401$.

Teece, D. J. and G. Pisano. (1994), 'The dynamic capabilities of firms, an introduction,' Industrial and Corporate Change, 3, 537-555.

Teece, D. J., G. Pisano and A. Shuen. (1997), 'Dynamic capabilities and strategic management,' Strategic Management Journal, 18, 509-533.

Vera, A. H. and H. A. Simon. (1993), 'Situated action: a symbolic interpretation,' Cognitive Science, 17, 7-48.

Winter, S. G. (2011), 'Problems at the foundation? Comments on Felin and Foss,' Journal of Institutional Economics, 7, $257-277$.

Winter, S. G. (2013), 'Habit, deliberation, and action: strengthening the microfoundations of routines and capabilities,' Academy of Management Perspectives, 27, 120-137.

Zollo, M. and S. G. Winter. (2002), 'Deliberate learning and the evolution of dynamic capabilities,' Organization Science, 13, 339-351. 